\title{
Neuregulin 4 (NRG4) - the batokine with clinical relevance in Gestational Diabetes Mellitus
}

Hira Attique ( $\nabla$ hira.attique@zu.edu.pk)

Ziauddin University

Saeeda Baig

Ziauddin University

Shahina Ishtiaque

Dr Ziauddin Hospital

Rehana Rehman

Aga Khan University

Tousif Ahmed

Ziauddin University

Moazzam Ali Shahid

Ziauddin University

Research article

Keywords: Adipose Tissue, Brown, Diabetes, Gestational, Pregnancy

Posted Date: August 28th, 2020

DOI: https://doi.org/10.21203/rs.3.rs-54591/v1

License: (c) (i) This work is licensed under a Creative Commons Attribution 4.0 International License.

Read Full License 
Neuregulin 4 (NRG4) - the batokine with clinical relevance in Gestational Diabetes Mellitus

\section{Authors:}

1. Dr. Hira Attique, MPhil Physiology, Department of Physiology Ziauddin University, Karachi Pakistan. hira.attique@ zu.edu.pk

2. Dr. Saeeda Baig, Professor and Head, Department Biochemistry, Ziauddin University Karachi Pakistan. saeeda.baig@ zu.edu.pk

3. Dr. Shahina Ishtiaque, Associate professor, Department of Gynea/Obs, Dr. Ziauddin Hospital, Karachi Pakistan. shahinazahoor@yahoo.com

4. Dr. Rehana Rehman, Associate Professor, Department of Biological and Biomedical Sciences, Agha Khan University Karachi Pakistan. $\underline{\text { rehana.rehman@aku.edu }}$

5. Syed Tousif Ahmed, Professor and Head of Department, Physiology Ziauddin University, Karachi Pakistan. drstzaidi@yahoo.com

6. Mr. Moazzam Ali Shahid, Research Officer, Department of Research, Ziauddin University Karachi Pakistan. moazzam.ali@zu.edu.pk

\section{Corresponding Author:}

Correspondence to Hira Attique. 


\begin{abstract}
Background: Neuregulin4 (NGR4) is a brown fat adipokine that modulates carbohydrate and lipid metabolism, regulate insulin sensitivity. The relationship between NGR4 and gestational diabetes mellitus (GDM) remains unclear due to discrepancy in studies. The objective of this study was to find out association between NRG4 and insulin level in women with GDM and their relationship with other metabolic parameters.
\end{abstract}

Methods: In this comparative cross sectional study, pregnant women $(\mathrm{n}=80)$, coming for regular antenatal check-ups between 24 and 28 weeks of gestation were recruited. After informed signed consent, interview based proforma was filled with demographic data and antenatal history. Anthropometric measurements were taken; weight recorded on first visit was considered pre-pregnancy weight. Blood $(5 \mathrm{ml})$ was drawn after 12 hours fast for estimation of fasting blood sugar (FBS), insulin, NRG4 and lipid profile and secondly after one hour post-consuming 50gm glucose, for glucose challenge test. Statistical analysis was done using SPSS version20, Mann Whitney and Spearman correlation for finding association between variables, whereas, Kruscal Wallis Test for differences between groups.

Results: Median NRG4 level (0.98) in healthy group was significantly high $(\mathrm{p}<0.038)$ compared to GDM (0.94). The NRG4 had inverse weak association with GDM. The mean insulin and homeostasis assessment model of insulin resistance (HOMA IR) values had weak direct association with NRG4. Cholesterol, LDL had inverse relationship with NRG4. All parameters of lipid profile were high in GDM compared to non GDM, but only cholesterol was statistically significant $(\mathrm{p}<0.03)$. The FBS in healthy group was significantly low $(\mathrm{p}<0.02)$ compared to GDM. The association between insulin and HOMA IR was statistically significant $(\mathrm{p}<0.05)$. The difference between BMI was statistically significant with age $(p<0.015)$, parity $(p<0.035)$. The difference between FBS and education was found significant $(\mathrm{p}<0.049)$.

Conclusion: Serum NRG4 level were found low in GDM compared to non-GDM $(\mathrm{p}<0.03)$, with a week and direct association with insulin. Future studies are required with bigger sample size to establish NRG4 as a potential biomarker for GDM.

Keywords: Adipose Tissue, Brown; Diabetes, Gestational; Pregnancy 


\section{Background:}

Gestational diabetes mellitus (GDM), the most common metabolic disease during pregnancy, has a prevalence of $8 \%$ in Pakistan [1], whereas, universally it is between 16-27\% [2]. Recently, a brown fat adipokine, neuregulin4 (NRG4), has been identified, related indirectly with patients having GDM, type1diabetes mellitus (T1DM), type2diabetes mellitus (T2DM),non-alcoholic fatty liver disease (NAFLD), and coronary artery diseases $[3,4]$.

NRG4, belongs to the epidermal growth factor (EGF) family of extracellular ligands [5]. Harari etal were the first to report NRG4, a fourth neuregulin, having high mRNA expression in the pancreas. They found out that NRG4 acts through ErbB-4 and its pattern of expression together with its strict specificity to growth factor, suggest a physiological role distinct from that of the known ErbB ligands [6]. NRG4 is secreted by all types of adipose tissues upon cold stimuli but is highly expressed in brown adipose tissue (BAT) [7]. NRG4 after release from the brown fat binds to EGF receptor ErbB4 (v-erb-b2 avian erythroblastic leukemia viral oncogene homolog 4) [4] present on the liver and inhibits de novo synthesis of lipids to get rid of high amount of lipids circulating in the blood and promotes fatty acid oxidation [8]. At the same time it increases glucose utilization through GLUT (glucose transporters) 1 and 4 for rapid uptake of glucose by the cells [9]. It is responsible for regulating the homeostasis of bodily metabolic responses either in a paracrine or endocrine manner [10]. NRG4 stimulates cell proliferation, inhibits apoptosis and improves cell energy metabolism4) It helps to mitigate hepatic lipogenic signaling, maintain lipid and glucose homeostasis, prevent obesity, and improve insulin resistance (IR) in mice [10]. Moreover, it has a role in angiogenesis and nerve innervation [10], and protects the intestinal epithelial cell from inflammation [11].

Limited research is available regarding NRG4 association with GDM, and that too with contradictory results. Women with GDM have sevenfold chances of developing T2DM in postpartum. Estimation of NRG4, if found low in GDM, it can be used as a possible biomarker for predicting the chance of developing diabetes postpartum [12]. Hence, through strict diet and lifestyle modification, during this time, NRG4 secretion can be enhanced to maintain glucose homeostasis. The objective of this study was to find out association between levels of NRG4 and insulin in women with GDM and to find out their relationship with other metabolic parameters. 


\section{Methods:}

This comparative cross sectional study was conducted from June 2018 to February 2019, after the approval from ethics review committee of Ziauddin University. Through a non- probability consecutive technique 84 pregnant women who came for their regular antenatal check-ups between 24 to 28 weeks of gestation were recruited from the gynaecology and obstetrics OPD and Family Medicine department at Dr. Ziauddin Hospital Karachi Pakistan, after they signed an informed consent. Sample size was calculated using open-epi calculator. Women with generalized or chronic inflammation, pre-existing diabetes, under treatment with anti-diabetic or insulinsensitizing agents were excluded.

An interview based proforma was filled with demographic data, anthropometric measurements, detailed antenatal and previous obstetric history. Weight recorded at the first visit was considered as pre pregnancy weight. Venous blood (5ml) was drawn after 12 hours fast for fasting blood glucose (FBS), insulin levels, NRG4 and lipid profile. All women were given $50 \mathrm{gm}$ glucose and $5 \mathrm{ml}$ blood after one hour was drawn for glucose challenge test (GCT). The flow chart of data collection procedure is shown in Figure1.

Body fat percentage and body mass index (BMI) was measured using bioelectrical impedance through Omron analyser (HBF 306C). BMI values which are recommended by WHO were considered normal. Body fat percentage values created by Gallagher et al were considered normal [13]. NRG4 and fasting insulin level was estimated using enzyme-linked immunosorbent assays (ELISAs) as per the manufacturer's instructions (Phoenix Pharmaceuticals, Burlingame, CA,USA) and chemiluminescnce (Siemens IMMULITE®1000Chemiluminescent) respectively. Lipid profile was done using Merck's company semi-automated spectrophotometric analyzer at 546nm wavelength. Lipid profile values were considered normal that are recommended by National Cholesterol Education Program's (NCEP's) ATPIII (Adult Treatment Panel III) guidelines 2018 for managing cholesterol in adults. FBS normal value were taken normal according to American diabetic association (ADA) 2019 guidelines, FBS between $100-126 \mathrm{mg} / \mathrm{dl}$ as pre-diabetic and greater than $126 \mathrm{mg} / \mathrm{dl}$ as diabetic. GCT values were taken normal according to American diabetic association (ADA) 2019 guidelines. 
Statistical program for social science (SPSS) version 20 was used for data analysis. The quantitative variables were expressed as median (interquartile ranges). 84 pregnant women were divided into two groups using Mann Whitney's Test to find the association of quantitative parameters between the GDM and healthy group. Spearman Correlation was used to find an association of NRG4 and insulin with GDM and metabolic parameters and Kruscal Wallis Test to find the difference between age, parity, education and ethnicity with glucose and non-glucose parameters. $\mathrm{P}$ value less than 0.05 was considered statistically significant.

\section{$\underline{\text { Results: }}$}

Out of 84 subjects, 37 had GDM with a significant low ( $p$ 0.038) median (interquartile range) NRG4 level of $0.94(0.08) \mathrm{ng} / \mathrm{ml}$ compared to 47 healthy pregnant women [NRG4 0.98(0.10)ng/ml]. The FBS in healthy group was significantly low ( $p 0.02)$ compared to GDM. The mean insulin and HOMA IR values between two groups were non-significant. (Table1)

Median cholesterol was statistically high $(p<0.03)$ in GDM [220(66.50)mg/dl] compared to healthy pregnant women $[210(64) \mathrm{mg} / \mathrm{dl}]$. Mean triglycerides (TGs), low density lipoproteins (LDL), high density lipoproteins (HDL) and very low density lipoproteins (VLDL) were also high in GDM but the results were not significant. (Table1).

Insulin had significant strong direct association with body fat $\%$ whereas with cholesterol, HDL and LDL had a significant inverse association. BMI had significantly associated with body fat and FBS. GCT was directly associated with HOMAIR, FBS, cholesterol, TGs, and LDL with p value < 0.05(Table2)

NRG4 was found to have indirect association with GDM. (Figure2)

NRG4 was found to have weak direct association with insulin, homeostasis assessment model of insulin resistance (HOMA IR). Cholesterol and LDL had an inverse weak association. NRG4 had no association with FBS, BMI, TGs and HDL. (Table2 and 3)

Relationship of BMI with age and parity was found significant with $\mathrm{p}<0.015$ and $\mathrm{p}<0.035$ ) respectively. (Table4)

Association between insulin and HOMA IR is shown in Figure3. 


\section{Discussion:}

Novel BAT-secreted adipokine NRG4 was found indirectly associated with GDM in this study. This is the first study in the Pakistani population evaluating NRG4 in GDM. Consistent with the preceding research of Karlish et al [3] we observed significantly lower levels of plasma NRG4 in women with GDM compared to the healthy pregnant non GDM females. Many experimental studies on animals and human have revealed the association between NRG4 and glucose levels, but the majority of the researchers are uncertain about the exact mechanism of underlying association. However, research on exploring its relationship with glucose metabolism revealed the underlying metabolic pathways that are involved in glucose and fat homeostasis [10].

Microarray analysis used on mouse model revealed that an over expression of NRG4 leads to decreased expression of enzymes required for gluconeogenesis in the liver [14]. These researches on animals studied the expressions of NRG4 levels in the tissue than its concentration in the plasma. Glucose tolerance on NRG4 knockout mice and observation on high glucose levels after feeding high fat diet demonstrated that transgenic mice with high expressions of NRG4 had low glucose concentration compared to control wild type mice showing involvement of NRG4 in glucose and fat homeostasis [10]. In contrast one study conducted by Kurek et al in 2017, regarding association of NRG4 with GDM published contradictory findings, showing significant elevation in NRG4 levels in GDM pregnant females. The divergence in their findings might be due to difference in methodology, genetic, racial or lifestyle differences in the study population.

The role of NRG4 at maintaining lipid and glucose homeostasis suggest that NRG4 may work as a defending metabolic adipokine. In obese mice low expressions of mRNA of NRG4 were observed which caused fatty liver, dyslipidemia and increased IR $[10,15]$. This establishes an inverse relation of NRG4 with FBS and body fat mass [5]. Studying the lipid profile reveals that NRG4 has an inverse relation with TGs but is directly related to HDL [12]. This explains why obese human beings in general have low NRG4 levels along with negative correlation with dyslipidemia and IR [10].We found an inverse association of NRG4 with Cholesterol and LDL in our study. However, association of NRG4 with insulin and HOMA IR was found direct but it was not significant. 
The relationship of NRG4 with diabetes has been ascertained by studying its correlation with FBS, metabolic and other parameters. Majority of the researchers observed low expressions of NRG4 mRNA in visceral and subcutaneous adipose tissue of individuals with impaired glucose tolerance and T2DM, even patients with newly diagnosed T2DM were found to have low NRG4 levels [16]. Whereas, fasting glucose, fasting insulin and HOMA IR were indirectly associated with NRG4. Researchers concluded that serum NRG4 level is elevated in pre-diabetics and diabetics. In Chinese population comparison of quartiles of serum NRG4 concentrations showed an odds ratio (OR) of 3.005 in diabetes prevalence, after adjusting age and gender. However, other parameters were also found significantly correlating with serum NRG4 ( $\mathrm{P}<0.05)$, including BMI, alanine aminotransferase, HDL, TGs, uric acid, GFR etc. [17] In our study we did not observe any association of NRG4 with FBS, TGs, and HDL. All the results were statistically not significant.

A number of studies investigated association of circulating NRG4 levels on metabolic diseases such as NAFLD, GDM, obesity and T2DM [3,12,18,19]. Regarding Metabolic syndrome (MS), NRG4 in various studies was shown strongly associated. Researchers assert that the OR remained significant for the association of plasma NRG4 concentration with the presence of MS even after adjusting the potential confounders, including all measures of IR. This shows that low levels of NRG4 in plasma is adding to the risk of MS independently of IR, suggesting that plasma NRG4 may protect against MS via IR-independent mechanisms. Experimental evidence suggests that compounding factor for MS oxidative stress which is increased by reduction in antioxidant defenses established by correlation of high inflammation status (IR, T2DM, hypertension, obesity and dyslipidemia) and decrease in levels of antioxidant enzymes [20]. This occurs through down regulation of NRG4 gene expression in patients with high oxidative stress [21]. Yan et al's studies [12] on NRG4 levels in T2DM with and without MS revealed that T2DM with MS had low levels of NRG4. This shows that decrease in NRG4 levels is playing a crucial part in the pathophysiology of MS. Presence of NRG4 in blood helps in maintaining metabolic balance of glucose and lipids in both animal and humans hence preventing or delaying the detrimental effects of metabolic diseases.

In our study HOMA IR and fasting insulin levels were directly related to circulating NRG4 in blood as documented by Kurek et al. [22] NRG4, maintains lipid and glucose homeostasis through ERB3 and ERB4 receptors present in the liver. It also up 
regulates GLUT1 and GLUT3 transporters in skeletal muscle to increase glucose uptake hence maintaining glucose homeostasis $[5,10]$. The insight in target receptors of NRG4, can therefore, lead to hypothesis that NRG4 is involved in glucose and fat homeostasis. However, the exact mechanism of NRG4 is still not fully understood. Overall, studies conducted on NRG4, so far had diverse variables such as varying sample size, ELISA techniques, and patient characteristics; and ethnic disparity and hence results are also discrepant. Secondly, the pathophysiological processes of metabolic diseases are possibly affecting the signaling pathways activating NRG4 release or maybe they are creating its resistance at the level of receptor are a cause of low or high levels of NRG4 in metabolic diseases. There are some limitations in this study. The study sample size was small, NRG4 cut-off value could not be calculated and used GCT for diagnosis of GDM rather than OGTT.

\section{Conclusion:}

The study concludes that since NRG4 was found high in healthy women compared to GDM, therefore, rise in NRG4 can improve glucose status in patients with GDM. This suggests that awareness sessions could be conducted amongst pregnant women and who plan to conceive to increase brown fat activity through strictly modifying diet and lifestyle. Enhanced NRG4 secretion maintain glucose homeostasis and chances of complications during pregnancy may be avoided. Future studies, with bigger sample size are required to establish NRG4 as a potential biomarker for GDM.

\section{Abbreviations:}

NRG4: Neureglin4

GDM: Gestational diabetes mellitus

T1DM: Type1 diabetes mellitus

T2DM: Type2 diabetes mellitus

NAFLD: Non-alcoholic fatty liver disease

EGF: Epidermal growth factor

BAT: Brown adipose tissue

IR: Insulin resistance

FBS: Fasting blood sugar

GCT: Glucose challenge test

BMI: Body mass index

HOMA IR: Homeostatic model assessment of insulin resistance 
TGs: Triglycerides

LDL: Low density lipoproteins

HDL: High density lipoproteins

VLDL: Very low density lipoproteins

OD: Odds ratio

MS: Metabolic syndrome

\section{DECLARATIONS:}

\section{Ethics approval and consent to participate:}

This study was approved by ethics review committee of Ziauddin University Pakistan. Verbal and written signed consent was taken from all the patients.

\section{Consent for publication:}

Not applicable

3. Availability of data and materials:

The datasets used and/or analyzed during the current study are available from the corresponding author on reasonable request.

\section{Competing interests:}

The authors declare that they have no competing interests.

\section{Funding:}

Ziauddin University gave Rs. 1, 50,000 as a seed money for the project. Rest was self-financed.

6. Author's contribution: HA conceived the idea and did bench work and statistics. SI contributed in sample collection/patient counseling. SB contributed in sampling and manuscript writing. STA and RR contributed in writing and overall formatting. MAS contributed in sample collection and bench work.

7. Acknowledgement: Authors acknowledge Mr. Waqar, Miss Shehla, Dr. Leena Hani, Dr. Adnan Zuberi and Ms. Saro for assisting in sample collection and bench work.

\section{References:}

1. Jawa A, Raza F, Qamar K, Jawad A, Akram J. Gestational diabetes mellitus is rare in primigravida Pakistani women. Indian journal of endocrinology and metabolism. 2011;15(3):191. doi:10.4103/2230-8210.83404. 
2. Ferrara A. Increasing prevalence of gestational diabetes mellitus: a public health perspective. Diabetes care. 2007;30 Suppl 2:S141-6. doi: 10.2337/dc07-s206.

3. Kralisch S, Hoffmann A, Kratzsch J, et al. The brown-fat-secreted adipokine neuregulin 4 is decreased in gestational diabetes mellitus. Diabetes Metab. 2018;44(2):150-154. doi:10.1016/j.diabet.2017.06.001

4. Yang F, Li X. Research progress of neuregulin 4 biological function. Sheng li xue bao:[Acta physiologica Sinica]. 2017;69(3):351-6.

5. Cai C, Lin M, Xu Y, Li X, Yang S, Zhang H. Association of circulating neuregulin 4 with metabolic syndrome in obese adults: a cross-sectional study. BMC Medicine. 2016;14(1):165. doi:10.1186/s12916-016-0703-6.

6. Harari D, Tzahar E, Romano J, Shelly M, Pierce JH, Andrews GC, et al. Neuregulin-4: a novel growth factor that acts through the ErbB-4 receptor tyrosine kinase. Oncogene. 1999;18:2681. doi:10.1038/sj.onc.1202631.

7. Pfeifer A. NRG4: an endocrine link between brown adipose tissue and liver. Cell metabolism. 2015;21(1):13-4. doi:10.1016/j.cmet.2014.12.008.

8. Bartelt A, Bruns OT, Reimer R, et al. Brown adipose tissue activity controls triglyceride clearance. Nat Med. 2011;17(2):200-205. doi:10.1038/nm.2297

9. van Dam AD, Kooijman S, Schilperoort M, Rensen PC, Boon MR. Regulation of brown fat by AMP-activated protein kinase. Trends Mol Med. 2015;21(9):571-9. doi:10.1016/j.molmed.2015.07.003.

10. Wang GX, Zhao XY, Meng ZX, et al. The brown fat-enriched secreted factor $\mathrm{Nrg} 4$ preserves metabolic homeostasis through attenuation of hepatic lipogenesis. Nat Med. 2014;20(12):1436-1443. doi:10.1038/nm.3713

11. McElroy SJ, Castle SL, Bernard JK, Almohazey D, Hunter CJ, Bell BA, et al. The ErbB4 ligand neuregulin-4 protects against experimental necrotizing enterocolitis. The American journal of pathology. 2014;184(10):276878. doi: 10.1016/j.ajpath.2014.06.015.

12. Yan $\mathrm{P}, \mathrm{Xu} \mathrm{Y}$, Wan Q, et al. Plasma Neuregulin 4 Levels Are Associated with Metabolic Syndrome in Patients Newly Diagnosed with Type 2 Diabetes Mellitus. Dis Markers. 2018;2018:6974191. doi:10.1155/2018/6974191

13. Dympna Gallagher, Steven B Heymsfield, Moonseong Heo, Susan A Jebb, Peter R Murgatroyd, Yoichi Sakamoto. Healthy percentage body fat ranges: an approach for developing guidelines based on body mass index, The American Journal of Clinical Nutrition. 2000; 72(3):694-701. https://doi.org/10.1093/ajcn/72.3.694

14. Zhang L, Bai M, Tang H, Zhou F, Zhu Q, Wang S, et al. Role of hepatic neuregulin 4 in the regulation of gluconeogenesis in mice. Life sciences. 2019;217:185-92. doi:10.1016/j.lfs.2018.12.006. 
15. Ma Y, Gao M, Liu D. Preventing High Fat Diet-induced Obesity and Improving Insulin Sensitivity through Neuregulin 4 Gene Transfer. Sci Rep. 2016;6:26242. doi:10.1038/srep26242

16. Zhang L, Fu Y, Zhou N, Cheng X, Chen C. Circulating neuregulin 4 concentrations in patients with newly diagnosed type 2 diabetes: a cross-sectional study. Endocrine. 2017;57(3):535-8. doi:10.1007/s12020-017-1324-3.

17. Chen LL, Peng MM, Zhang JY, et al. Elevated circulating Neuregulin4 level in patients with diabetes. Diabetes Metab Res Rev. 2017;33(4):10.1002/dmrr.2870. doi:10.1002/dmrr.2870

18. Jiang J, Lin $\mathrm{M}, \mathrm{Xu} \mathrm{Y}$, et al. Circulating neuregulin 4 levels are inversely associated with subclinical cardiovascular disease in obese adults. Sci Rep. 2016;6:36710. doi:10.1038/srep36710

19. Dai Y-N, Zhu J-Z, Fang Z-Y, Zhao D-J, Wan X-Y, Zhu H-T, et al. A case-control study: Association between serum neuregulin 4 level and non-alcoholic fatty liver disease. Metabolism. 2015;64(12):1667-73. https://doi.org/10.1016/j.metabol.2015.08.013.

20. Chen S-J, Yen C-H, Huang Y-C, Lee B-J, Hsia S, Lin P-T. Relationships between inflammation, adiponectin, and oxidative stress in metabolic syndrome. PloS one. 2012;7(9):e45693. https://doi.org/10.1371/journal.pone.0045693.

21. Slattery ML, Pellatt DF, Mullany LE, Wolff RK. Differential gene expression in colon tissue associated with diet, lifestyle, and related oxidative stress. PloS one. 2015;10(7):e0134406. https://doi.org/10.1371/journal.pone.0134406.

22. Kurek Eken M, Yayla Abide C, Sahin Ersoy G, Altun Ensari T, Pekin O, Cevik O. Clinical significance of neuregulin 4 (NRG4) in gestational diabetes mellitus. Gynecol Endocrinol. 2017:1-4. doi:10.1080/09513590.2017.1420772. 
Table1: Comparison of Diabetic Parameters in pregnant females with and without GDM.

\begin{tabular}{|c|c|c|c|}
\hline \multirow{2}{*}{ Variables } & \multicolumn{2}{|c|}{ Median(Interquartile Range) } & \multirow{2}{*}{ P-Value } \\
\hline & Non-GDM(47) & GDM(37) & \\
\hline NRG4 (ng/ml) & $0.98(0.10)$ & $0.94(0.08)$ & $0.038^{*}$ \\
\hline FBS(mg/dl) & $79(18)$ & $92(36)$ & $0.020^{*}$ \\
\hline BMI (kg/m2) & $24.20(6)$ & 25.7(7.90) & 0.238 \\
\hline $\operatorname{Insulin}(\mu \mathrm{U} / \mathbf{m l})$ & $3.92(3.58)$ & $4.74(6.19)$ & 0.428 \\
\hline HOMA IR & $0.75(0.80)$ & $1.02(1.84)$ & 0.093 \\
\hline Body Fat (\%) & 26(11.90) & $28.10(11.95)$ & 0.296 \\
\hline $\begin{array}{l}\text { Cholesterol } \\
\text { (mg/dl) }\end{array}$ & $210(64)$ & $220(66.50)$ & $0.030^{*}$ \\
\hline TGs (mg/dl) & $170(41)$ & 174(49.50) & 0.151 \\
\hline HDL (mg/dl) & $51(11)$ & $52(10.50)$ & 0.407 \\
\hline LDL(mg/dl) & $114.20(44)$ & $133.20(64.50)$ & 0.135 \\
\hline VLDL(mg/dl) & $34(8.20)$ & $34.80(9.90)$ & 0.151 \\
\hline
\end{tabular}

Mann- Whitney’s Test. *P $<0.05$ statistically significant

Table 2: Association of Different Variables with NRG4

\begin{tabular}{|c|c|c|c|c|c|c|c|c|}
\hline \multirow[b]{2}{*}{ Variables } & \multicolumn{2}{|c|}{ NRG4 } & \multicolumn{2}{|c|}{ Insulin } & \multicolumn{2}{|c|}{ BMI } & \multicolumn{2}{|c|}{ GCT } \\
\hline & $\mathbf{R}$ & $\begin{array}{c}P \\
\text { value }\end{array}$ & $\mathbf{r}$ & $\begin{array}{c}P \\
\text { value }\end{array}$ & $\mathbf{r}$ & $\begin{array}{c}P \\
\text { value }\end{array}$ & $\mathbf{r}$ & $\begin{array}{c}P \\
\text { value }\end{array}$ \\
\hline HOMA IR & 0.13 & 0.115 & 0.94 & 0.04 & $0.215^{*}$ & 0.025 & $0.235^{*}$ & 0.16 \\
\hline Body fat $\%$ & 0.07 & 0.264 & $0.19 *$ & 0.042 & $0.665 * *$ & 0.000 & 0.86 & 0.218 \\
\hline FBS (mg/dl) & 0.069 & 0.268 & 0.16 & 0.071 & $0.240 *$ & 0.014 & $0.311 * *$ & 0.002 \\
\hline Cho(mg/dl) & -0.14 & 0.102 & $-0.24 *$ & 0.013 & -0.051 & 0.324 & $0.269 * *$ & 0.007 \\
\hline TGs(mg/dl) & -0.02 & 0.419 & 0.07 & 0.254 & -0.061 & 0.289 & $0.243 *$ & 0.13 \\
\hline HDL(mg/dl) & -0.09 & 0.185 & -0.15 & 0.084 & -0.021 & 0.425 & -0.009 & 0.467 \\
\hline LDL(mg/dl) & -0.12 & 0.138 & $-0.26 * *$ & 0.008 & -0.013 & 0.453 & $0.213 *$ & 0.026 \\
\hline
\end{tabular}

Spearman correlation

** correlation is significant at 0.01 level. * correlation is significant at 0.05 level $* \mathrm{P}$ value $<0.05$ statistically significant 
Table3: Association of Different Variables with NRG4

\begin{tabular}{|l|c|c|}
\multicolumn{1}{l}{ Parameters } & P & P-Value \\
\hline Insulin $(\boldsymbol{\mu U} / \mathbf{m l})$ & 0.170 & 0.062 \\
\hline BMI & 0.021 & 0.423 \\
\hline Spearman correlation & & \\
\hline
\end{tabular}

Table4: Quantitative Variable of the Study population

\begin{tabular}{|c|c|c|c|c|c|c|c|c|c|c|c|}
\hline $\begin{array}{c}\text { Variab } \\
\text { le } \\
{[\mathrm{N}} \\
(\%)]\end{array}$ & $\begin{array}{l}\text { NRG4 } \\
(\mathrm{ng} / \mathrm{ml})\end{array}$ & $\begin{array}{l}\text { Body } \\
\text { fat }(\%)\end{array}$ & & BMI & \multicolumn{3}{|c|}{$\begin{array}{l}\text { FBS } \\
(\mathrm{mg} / \mathrm{dl} \\
)^{2}\end{array}$} & $\begin{array}{l}\text { sulin } \\
\mathrm{U} / \mathrm{ml}\end{array}$ & \multicolumn{2}{|c|}{ HOMAIR } & $\begin{array}{l}\text { GCT } \\
(\mathrm{mg} / \mathrm{dl})\end{array}$ \\
\hline \multicolumn{12}{|l|}{ AGE } \\
\hline $\begin{array}{c}\leq 20 \\
{[22(2} \\
0.8]\end{array}$ & $\begin{array}{l}0.99[0.1 \\
0]\end{array}$ & $\begin{array}{l}26.25 \\
{[10.7} \\
7]\end{array}$ & \multicolumn{2}{|c|}{$22.45[9.40]$} & \multicolumn{3}{|c|}{$90[24]$} & \multicolumn{2}{|c|}{$2.75[2.88]$} & $\begin{array}{l}0.65[0 . \\
65]\end{array}$ & $\begin{array}{l}133[32 . \\
25]\end{array}$ \\
\hline $\begin{array}{c}21-30 \\
{[49(46 .} \\
2]\end{array}$ & $\begin{array}{c}0.97[0.1 \\
0]\end{array}$ & $\begin{array}{l}28.2 \\
{[12.7} \\
5]\end{array}$ & \multicolumn{2}{|c|}{$25.70[8.20]$} & \multicolumn{3}{|c|}{$81[22]$} & \multicolumn{2}{|c|}{$4.61[5.26]$} & $\begin{array}{l}1.02[1 . \\
11]\end{array}$ & $\begin{array}{l}132[29 . \\
50]\end{array}$ \\
\hline $\begin{array}{c}\geq 31 \\
{[13(12 .} \\
3)]\end{array}$ & $\begin{array}{c}0.92[0.1 \\
8]\end{array}$ & $\begin{array}{l}28.1 \\
{[15.6} \\
5]\end{array}$ & \multicolumn{2}{|c|}{$26.7[6.45]$} & \multicolumn{3}{|c|}{$77[26]$} & \multicolumn{2}{|c|}{$3.97[19.01]$} & $\begin{array}{l}0.68[0 . \\
69]\end{array}$ & $\begin{array}{l}150[35 \\
]\end{array}$ \\
\hline $\begin{array}{c}\text { P- } \\
\text { Value }\end{array}$ & 0.153 & 0.097 & \multicolumn{2}{|c|}{$0.015^{*}$} & \multicolumn{3}{|c|}{0.309} & \multicolumn{2}{|c|}{0.070} & 0.136 & 0.828 \\
\hline \multicolumn{12}{|c|}{ PARITY } \\
\hline $\begin{array}{l}\text { Nullip } \\
\text { ara } \\
20(18 \\
.9)\end{array}$ & $\begin{array}{c}0.98[0 \\
.14]\end{array}$ & \multicolumn{2}{|l|}{$\begin{array}{l}24.25[11.2 \\
3]\end{array}$} & $\begin{array}{l}22.1[4 . \\
85]\end{array}$ & \multicolumn{2}{|c|}{$\begin{array}{l}83[31 . \\
5]\end{array}$} & \multicolumn{2}{|c|}{$3.47[3.21]$} & \multicolumn{2}{|c|}{$0.68[0.79]$} & $\begin{array}{l}127.5[29 \\
]\end{array}$ \\
\hline $\begin{array}{c}\text { Primip } \\
\text { ara } \\
16 \\
(15.1 \\
)\end{array}$ & $\begin{array}{c}1.01[0 \\
.14]\end{array}$ & \multicolumn{2}{|l|}{$\begin{array}{l}27.05[11.0 \\
3]\end{array}$} & $\begin{array}{l}24.35[3 \\
.38]\end{array}$ & \multicolumn{2}{|c|}{$\begin{array}{l}83.5[1 \\
7]\end{array}$} & \multicolumn{2}{|c|}{$4.69[5.13]$} & \multicolumn{2}{|c|}{$0.96[0.75]$} & $\begin{array}{l}129.5[24 \\
.25]\end{array}$ \\
\hline $\begin{array}{l}\text { Multip } \\
\text { ara } \\
37 \\
(34.9 \\
)\end{array}$ & $\begin{array}{c}0.95[0 \\
.09]\end{array}$ & \multicolumn{2}{|l|}{$28[11.75]$} & $\begin{array}{l}26.7[6 . \\
55]\end{array}$ & \multicolumn{2}{|c|}{$79[22]$} & \multicolumn{2}{|c|}{$4.25[5.43]$} & \multicolumn{2}{|c|}{$\begin{array}{c}.86[1.26 \\
]\end{array}$} & $\begin{array}{l}139[35.5 \\
]\end{array}$ \\
\hline $\begin{array}{l}\text { Grand } \\
\text { multip } \\
\text { ara } \\
11(10 . \\
4)\end{array}$ & $\begin{array}{l}0.96[0 . \\
06]\end{array}$ & $32.5[19]$ & & $\begin{array}{l}25[16.5 \\
]\end{array}$ & \multicolumn{2}{|c|}{$84[63]$} & \multicolumn{2}{|c|}{$3.5[3.53]$} & \multicolumn{2}{|c|}{$0.72[0.44]$} & $153[58]$ \\
\hline $\begin{array}{l}\text { P- } \\
\text { Value }\end{array}$ & 0.362 & 0.116 & & $0.035^{*}$ & \multicolumn{2}{|l|}{0.816} & \multicolumn{2}{|c|}{0.416} & 0.57 & & 0.41 \\
\hline ETHNI & CITY & & & & & & & & & & \\
\hline $\begin{array}{l}\text { Urdu } \\
\text { speaki } \\
\text { ng } \\
2(1.9 \\
)\end{array}$ & $\begin{array}{c}1.08[- \\
]\end{array}$ & 26.95 & & 21.05 & 60 & & 5.81 & & 0.90 & & 123.5 \\
\hline
\end{tabular}




\begin{tabular}{|c|c|c|c|c|c|c|c|}
\hline $\begin{array}{c}\text { Sindhi } \\
7 \\
(6.6)\end{array}$ & $\begin{array}{c}0.98[0 \\
.11]\end{array}$ & $25.5[9.90]$ & $\begin{array}{l}21.4[5 . \\
40]\end{array}$ & $75[24]$ & $2.71[7.39]$ & $0.46[2.07]$ & $125[38]$ \\
\hline $\begin{array}{l}\text { Punjab } \\
\text { i } \\
\quad 14 \\
(13.2 \\
\quad)\end{array}$ & $\begin{array}{c}0.93[0 \\
.14]\end{array}$ & $29[12.9]$ & $\begin{array}{l}25.95[6 \\
.02]\end{array}$ & $\begin{array}{l}79[21 . \\
25]\end{array}$ & $4.31[4.27]$ & $0.83[0.87]$ & $\begin{array}{l}1148[39 . \\
75]\end{array}$ \\
\hline $\begin{array}{l}\text { Pushtu } \\
61 \\
(57.5)\end{array}$ & $\begin{array}{l}0.97[0 . \\
1]\end{array}$ & $\begin{array}{l}27.6[13.10 \\
]\end{array}$ & $\begin{array}{l}24.59[6 \\
.50]\end{array}$ & $85[28]$ & $4.09[4.98]$ & $0.81[0.88]$ & $\begin{array}{l}137[28.5 \\
0]\end{array}$ \\
\hline $\begin{array}{l}\text { P- } \\
\text { Value }\end{array}$ & 0.44 & 0.458 & 0.105 & 0.099 & 0.938 & 0.861 & 0.093 \\
\hline \multicolumn{8}{|c|}{ EDUCATION } \\
\hline $\begin{array}{l}\text { Un- } \\
\text { educat } \\
\text { ed } \\
35(33 . \\
0)\end{array}$ & $\begin{array}{l}0.96[0.0 \\
6]\end{array}$ & $28.1[9.60]$ & $\begin{array}{l}25.3[7.8 \\
0]\end{array}$ & $83[31]$ & $3.5[3.52]$ & $0.74[0.74]$ & $127[40]$ \\
\hline $\begin{array}{l}\text { Relig } \\
\text { ion } \\
\text { study } \\
24(n)\end{array}$ & $\begin{array}{l}1.02[0 . \\
19]\end{array}$ & $\begin{array}{l}28.15[13.93 \\
]\end{array}$ & $\begin{array}{l}24.3[6.3 \\
2]\end{array}$ & $\begin{array}{l}86[18.7 \\
5]\end{array}$ & $4.85[5.67]$ & $1.03[1.23]$ & $\begin{array}{l}139.5[34 . \\
50]\end{array}$ \\
\hline $\begin{array}{l}\leq \text { Clas } \\
\text { s10 } \\
21(n)\end{array}$ & $\begin{array}{l}0.94[0 . \\
08]\end{array}$ & $22[10.80]$ & $\begin{array}{l}24.59[6 . \\
55]\end{array}$ & $\begin{array}{l}81(5.86 \\
)\end{array}$ & $4.25[5.86]$ & $0.89[0.98]$ & $\begin{array}{l}146[27.50 \\
]\end{array}$ \\
\hline $\begin{array}{l}\geq \\
\text { Class } \\
12^{\text {th }} \\
4(\mathrm{n})\end{array}$ & $\begin{array}{l}1.03[0.2 \\
8]\end{array}$ & $\begin{array}{l}23.55[17.63 \\
]\end{array}$ & $24[10]$ & $\begin{array}{l}68[0.75 \\
]\end{array}$ & $3.23[4.52]$ & $0.55[0.76]$ & $126[20]$ \\
\hline $\begin{array}{l}P- \\
\text { Value }\end{array}$ & 0.072 & 0.271 & 0.627 & $0.049 *$ & 0.668 & 0.495 & 0.068 \\
\hline
\end{tabular}

Kruscal Wallis Test; P- Value $<0.05$ is significant 
Pregnant subjects from OPD of Dr. Ziauddin Hospital

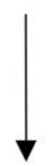

84 pregnant between 24 to 28 weeks of gestation

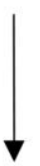

Interview based questionnaire was filled after informed consent

Height, Weight, BMI, Body fat

$5 \mathrm{ml}$ of blood was collected after 10-12 hours fasting for:

Lipid profile, Insulin, NRG4, FBS

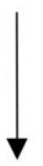

GCT was done for screening GDM

Figure1: Flow chart of study population 


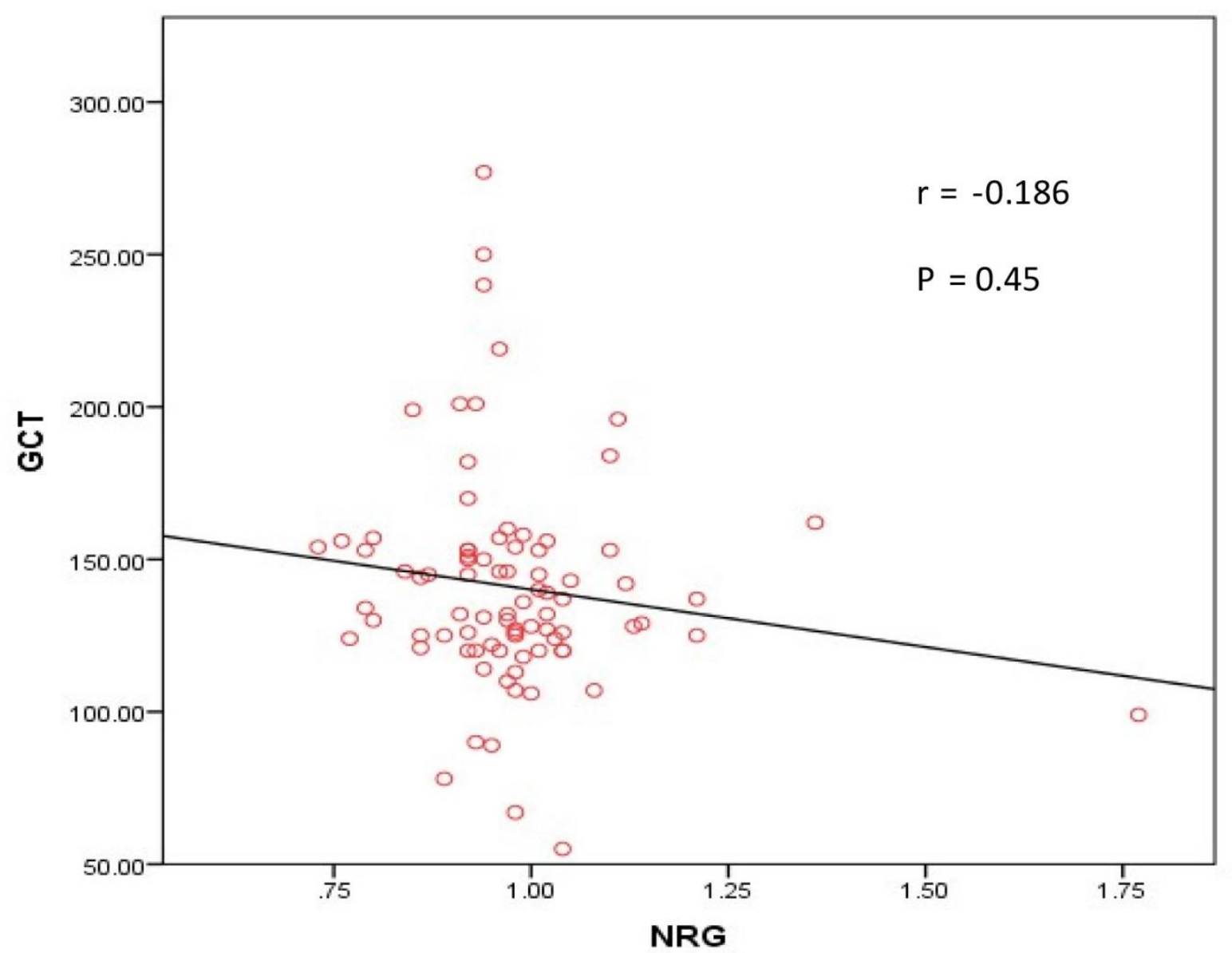

Figure2: Scatter Plot between NRG4 and GDM 


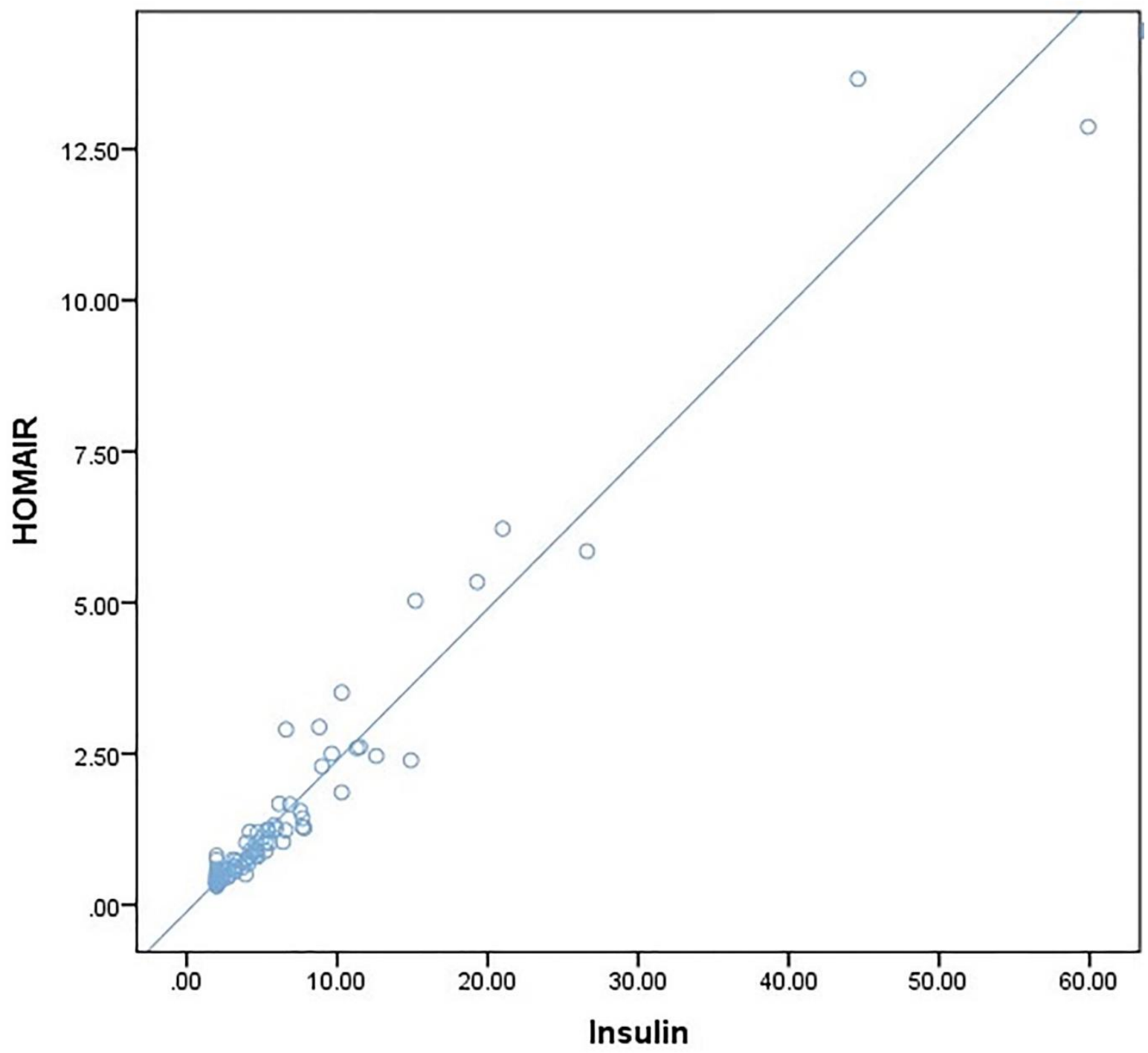

Figure3: Correlation of Insulin with HOMA IR 
Figures

Pregnant subjects from OPD of Dr. Ziauddin Hospital

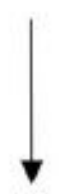

84 pregnant between 24 to 28 weeks of gestation

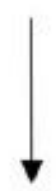

Interview based questionnaire was filled after informed consent

Anthropometric measurements:

Height, Weight, BMI, Body fat

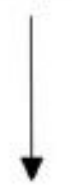

$5 \mathrm{ml}$ of blood was collected after 10-12 hours fasting for:

Lipid profile, Insulin, NRG4, FBS

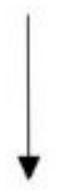

GCT was done for screening GDM

Figure 1

Flow chart of the study population 


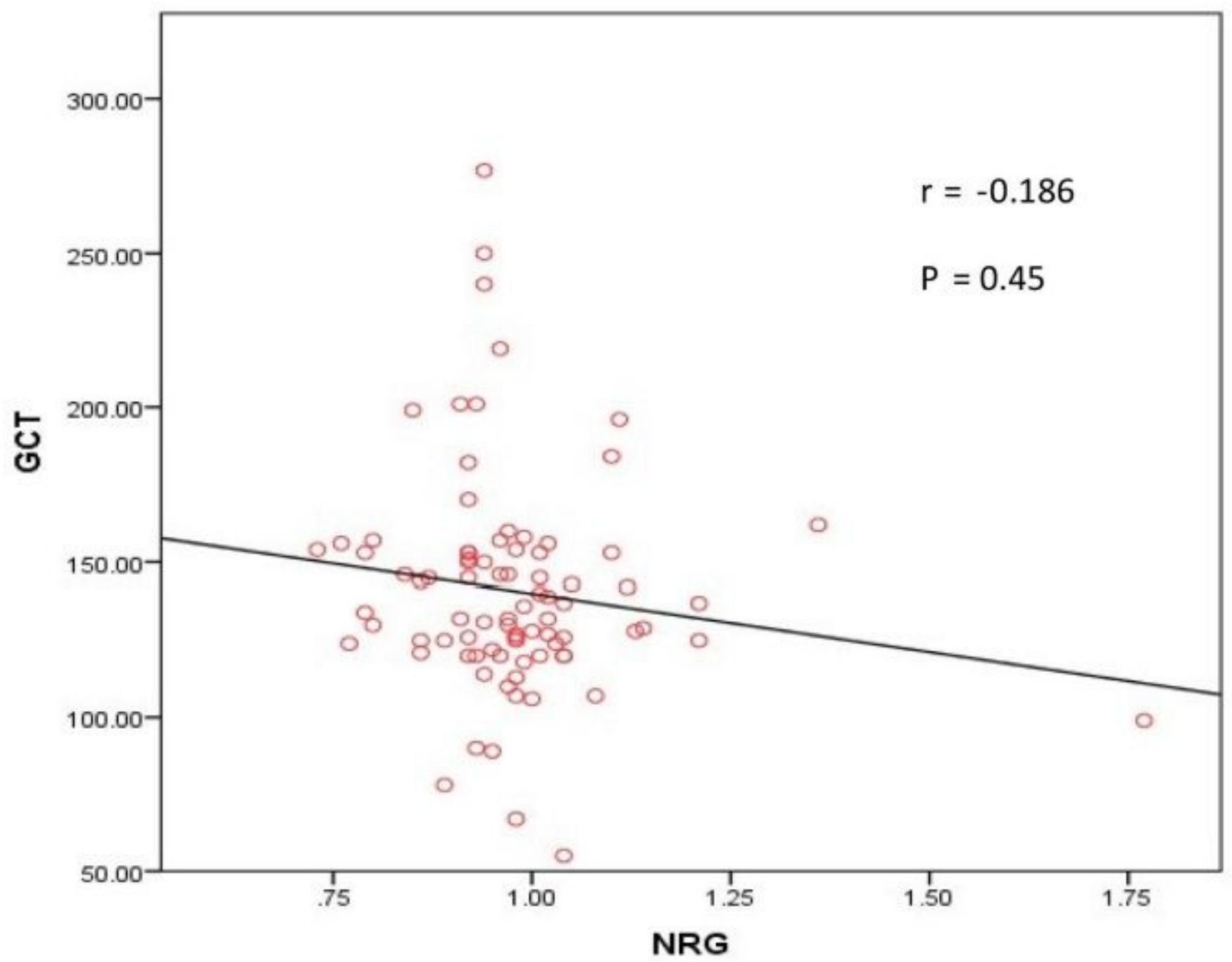

Figure 2

Scatter Plot between NRG4 and GDM 


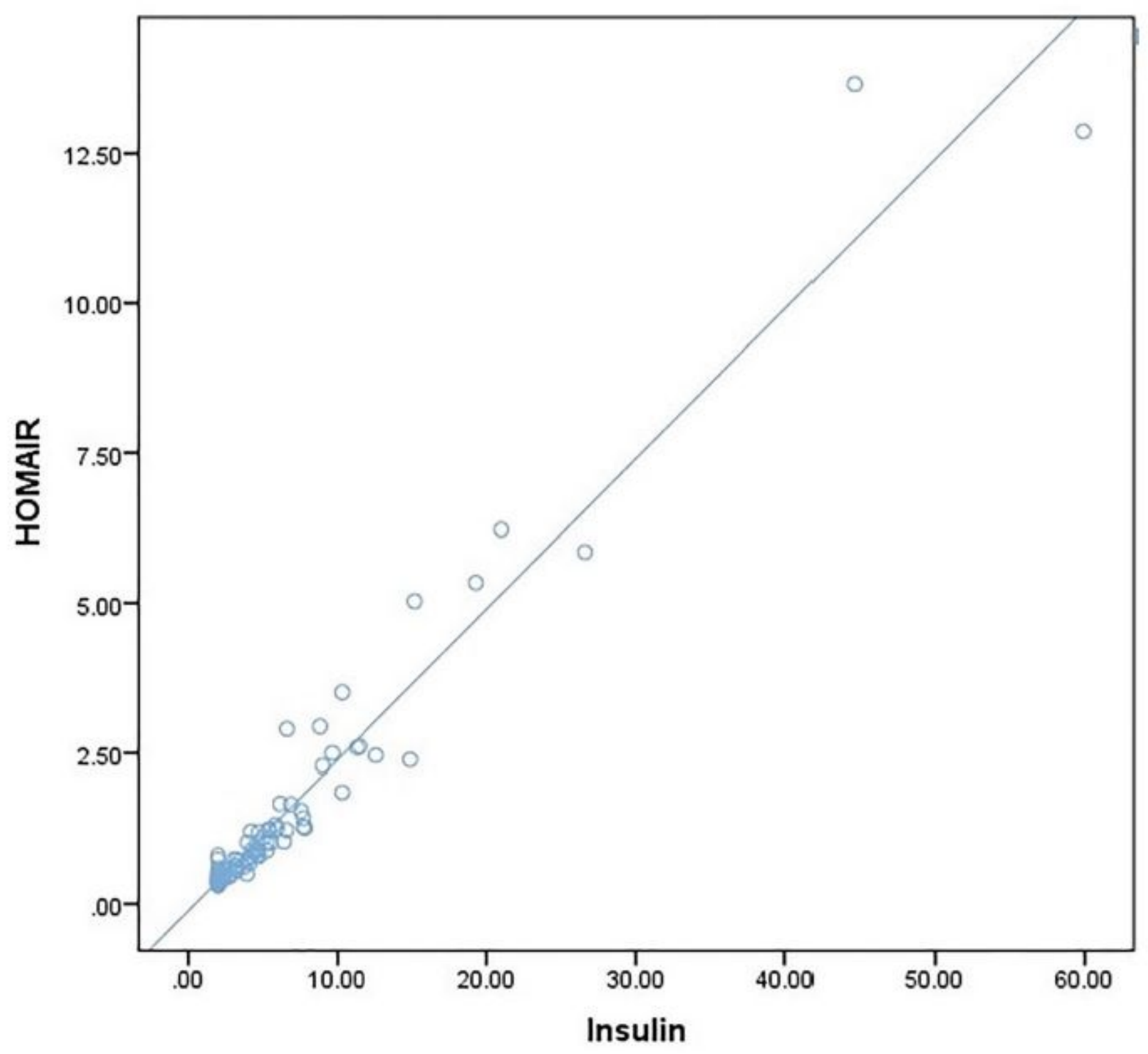

Figure 3

Correlation of Insulin with HOMA IR

\section{Supplementary Files}

This is a list of supplementary files associated with this preprint. Click to download.

- Questionnaire.pdf

- STROBEchecklist.pdf 